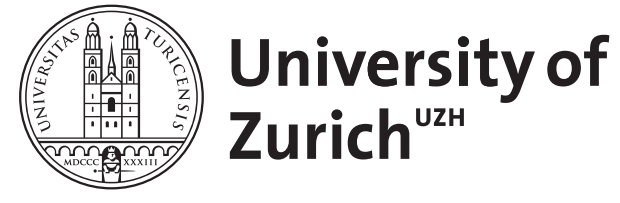

\title{
Rapid visual detection of blood cyanide
}

Maennel-Croise, Christine ; Zelder, Felix \begin{abstract}
equipment is described.
DOI: https://doi.org/10.1039/C2AY25595B

Posted at the Zurich Open Repository and Archive, University of Zurich ZORA URL: https://doi.org/10.5167/uzh-75059

Journal Article

Published Version
\end{abstract}

Abstract: The first method for the rapid visual detection of blood cyanide without the need of laboratory

Originally published at:

Maennel-Croise, Christine; Zelder, Felix (2012). Rapid visual detection of blood cyanide. Journal of Analytical Methods in Chemistry, 4(9):2632-2634.

DOI: https://doi.org/10.1039/C2AY25595B 
Analytical

Methods

C

$$
\text { C N }
$$

\section{$\mathrm{N}$}

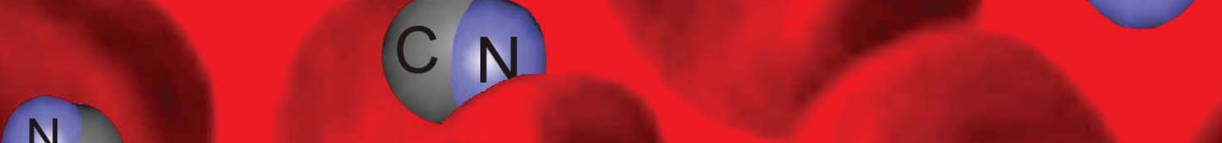

(

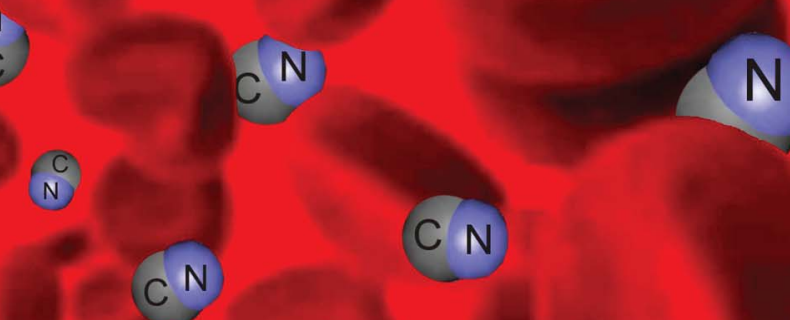

\section{C}

N

(

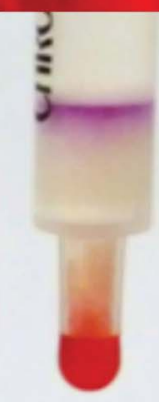

\section{N}

\section{$\mathrm{N}$}

C N

C

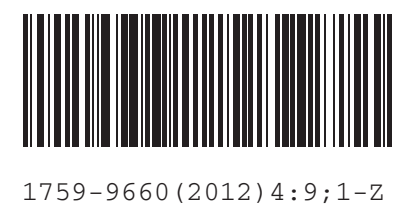




\title{
Analytical Methods
}

\section{Rapid visual detection of blood cyanide $\dagger$}

\author{
Christine Männel-Croisé and Felix Zelder* \\ Received 8th June 2012, Accepted 5th July 2012 \\ DOI: 10.1039/c2ay25595b
}

The first method for the rapid visual detection of blood cyanide without the need of laboratory equipment is described.

Cyanide poisoning is well-known from murderous detective stories, but arises mainly from smoke exposure in fire. ${ }^{1-3}$ Rapid absorption of $\mathrm{HCN}$ within the blood, its distribution into cells and binding to the ferric group of cytochrome oxidase inhibit cellular respiration and may lead to coma or death. ${ }^{4}$ The pathophysiology of acute cyanide poisoning occurs within seconds to minutes. ${ }^{5}$ Instantaneous diagnosis and treatment of fire-victims at the scene by paramedics are of utmost importance. ${ }^{3}$ Even though various time-consuming laboratory methods for the determination of blood cyanide exist, ${ }^{6-9}$ strategies for rapid detection in emergency situations are required. ${ }^{3}$ The administration of cyanide antidotes to fire-victims is therefore still based on a presumptive diagnosis. The development of a detection kit for blood cyanide will help to improve first-aid treatment of fire-victims with cyanide antidotes.

Herein, we report the first method to detect rapidly blood cyanide with colorimetric solid-phase extraction (Fig. 1). Only small quantities of blood $(V=0.5 \mathrm{ml})$ and no laboratory equipment are required.

In the first step, an orange-coloured metal-based chemosensor for cyanide is added to a blood sample (step A). In the presence of blood

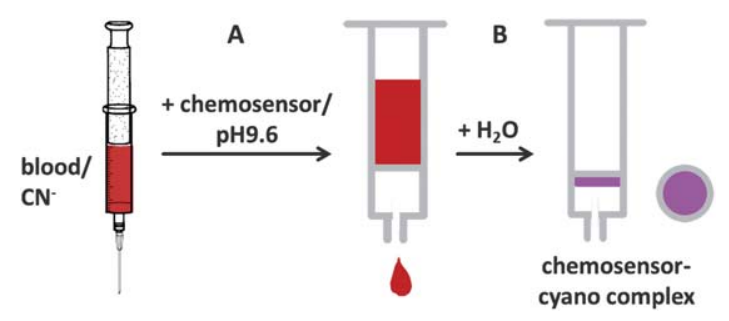

Fig. 1 Schematic overview of the two-step method for the visual detection of blood cyanide. (A) Addition of a chemosensor to a blood sample followed by selective solid-phase extraction of the violet-coloured chemosensor-cyano complex from the sample. (B) Washing the column with water.

Institute of Inorganic Chemistry, University of Zürich, Winterthurerstr. 190,8057 Zürich, Switzerland.E-mail: zelder@aci.uzh.ch; Web: http:// www.zelder.ch.vu; Fax: +41 4463 5463; Tel: +41 446354624

$\dagger$ Electronic supplementary information (ESI) available: Experimental part and additional Fig. S1-S5. See DOI: 10.1039/c2ay25595b cyanide, a chemosensor-cyano complex is formed and selectively extracted on the top of a white solid-support. Red coloured blood as opposed to the hydrophobic violet-coloured chemosensor-cyano complex - does not adsorb on the solid phase and can be easily removed by washing with water (step B). Semi-qualitative and quantitative determinations are possible.

In conventional applications, blood cyanide is detected after acidinduced release and separation of $\mathrm{HCN}$ from whole blood by microdiffusion or microdistillation. ${ }^{8,10}$ One of the few examples that lacks the microdiffusion stage is a LC-MS/MS detection method with naphthalene-2,3-dicarboxyaldehyde and taurine, as recently described by Lacroix et al. ${ }^{11} \mathrm{We}$ also aimed to reverse the order of the separation and detection steps thereby avoiding the formation of gaseous HCN under acidic conditions. In this approach, blood cyanide binds first to a metal-based chemosensor under homogenous conditions and is afterward separated from the sample by solid-phase extraction. Corrin-based chemosensors are ideal candidates for the detection of cyanide in complex, biological samples. ${ }^{12,13}$ Coordination of cyanide to aquacyano-corrinoids is fast and thermodynamically favourable $\left.\left(K=1.7 \times 10^{6} \mathrm{M}^{-1}\right)\right)^{14,15}$

We decided to apply a corrin derivative with seven hydrophobic methyl ester side chains to cyanide detection in regard of its extraction from blood with a C18ec column. The structure of the chemosensor 1 and the cyanide binding mechanism to form 1-CN is shown in Fig. S1 in the ESI. $\dagger$ This hydrophobic corrin derivative has not yet been applied to the detection of blood cyanide.

In a first experiment, we tested the extraction of the chemosensor $(n=41 \mathrm{nmol})$ from a blood sample $(V=0.5 \mathrm{ml})$ with a $\mathrm{C} 18 \mathrm{ec}$ column. ${ }^{16-18}$ The hydrophobic orange-coloured chemosensor with maxima at 356, 501 and $529 \mathrm{~nm}$ was partly adsorbed (yield: $50 \pm 5 \%$, $n=5$ ) on the upper part of the solid-phase as indicated by diffuse reflectance (DRUV-vis) spectroscopy (Fig. S2 $\dagger$ ). The quantification was performed with UV-vis spectrosocopy after eluting and converting 1 to $\mathbf{1 - C N}$ with excess cyanide. Compared to the complete extraction of the chemosensor from water, the low recovery rate from blood suggests losses during extraction. Protein's amino acid side chains in the plasma presumably bind to the cobalt centre of the complex. For example, thiolate ligation of corrinoids to the peptide glutathione in biological systems is well-known. ${ }^{19,20}$ Concentrations of glutathione in human whole blood are in the millimolar range and those in plasma are still in the micromolar range. ${ }^{21}$

Extraction of the chemosensor from cyanide spiked blood $\left(\left[\mathrm{CN}^{-}\right]=\right.$ $10-100 \mu \mathrm{M} ; V=0.5 \mathrm{ml}$ ) was tested afterward. ${ }^{16}$ This time, the violet coloured chemosensor-cyano complex 1-CN $\left(\lambda_{\max }=583 \mathrm{~nm}\right)$ was 


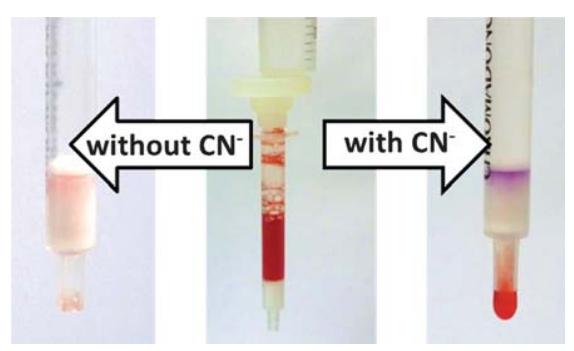

Fig. 2 Pictures of the experimental set-up for the detection of blood cyanide with chemosensor 1 according to Fig. 1. Comparison of the C18ec column upon passing blood without cyanide (left) and with spiked cyanide $\left(\left[\mathrm{CN}^{-}\right]=40 \mu \mathrm{M}\right.$; right $)$.

adsorbed on the top of the solid support (Fig. 2 right) indicating coordination of blood cyanide to 1 under homogenous conditions ( $\mathrm{pH}$ 9.6). Calibration curves were generated from plotting either the diffuse reflectance at $583 \mathrm{~nm}$ or the $b$-value of 1-CN versus different concentrations of cyanide (Fig. 3 and S3†). Linear responses between 0 and $50 \mu \mathrm{M}$ of cyanide were determined. These results are in agreement with the extraction of cyanide from water $(0.38 \%$ of sodium citrate) instead of blood (Fig. 3). The $b$-values were measured with a handheld spectrophotometer indicating differences of the blue colour in the CIELAB-system. In the DRUV-vis spectra, an increase of the absorption at 545 and $583 \mathrm{~nm}$ at increasing concentrations of cyanide with a detection limit of $3 \mu \mathrm{M}$ is observed (Fig. 4). In that case more chemosensor-cyano complex $\mathbf{1 - C N}$ is formed and extracted from the sample. This behaviour is reasonable since cyanide binds much stronger to corrinoids than any other ligands. ${ }^{22,23}$

The new method was compared to a microdistillation procedure using a cyanide-sensitive electrode. ${ }^{16} \mathrm{~A}$ very good correlation between both methods has been observed for blood samples spiked with different concentrations of cyanide (Fig. 5). ${ }^{16}$ Cyanide was also determined spectrophotometrically after eluting 1-CN from the solid support, meeting results from DRUV-vis measurements (Fig. S5†).

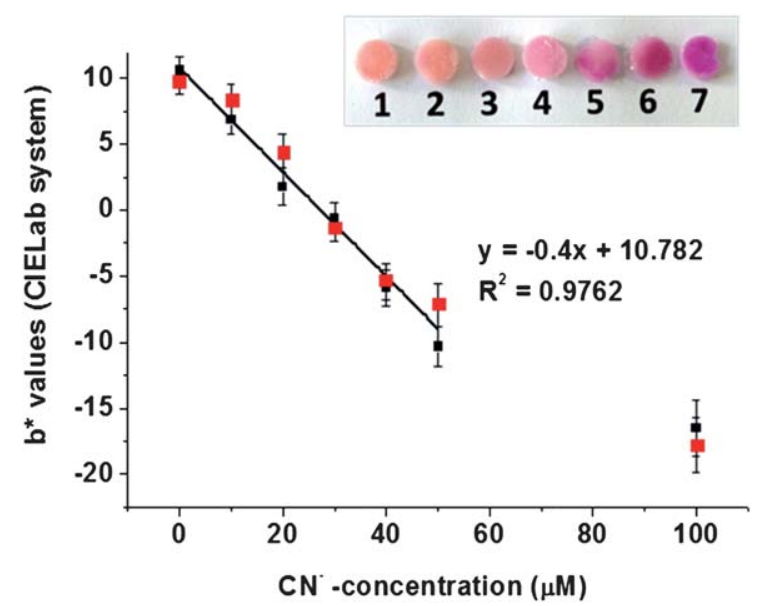

Fig. $3 B^{*}$-values (CIELab-system; $\left.n=3\right)$ vs. increasing concentrations of cyanide $\left(\left[\mathrm{CN}^{-}\right]=0-100 \mu \mathrm{M}\right)$ in blood (red quadrates, $V=0.5 \mathrm{ml}, \mathbf{1}=$ $42 \mathrm{nmol}$ ) and in water (black quadrates, $V=0.5 \mathrm{ml}, 0.38 \%$ vol. of sodium citrate, $1=42 \mathrm{nmol})$. Inset: corresponding pictures of the surfaces of the $\mathrm{C} 18 \mathrm{ec}$ material after blood cyanide detection according to Fig. 1. All measurements were performed 15 min after spiking. ${ }^{16}$

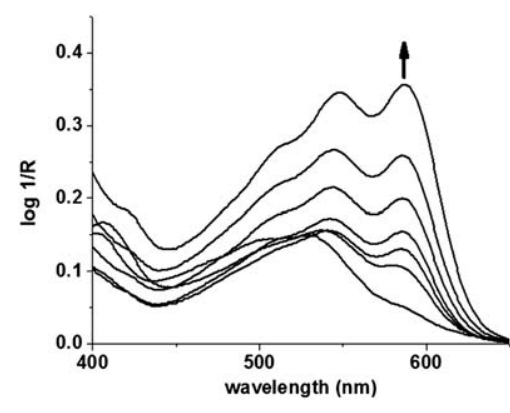

Fig. 4 DRUV-vis spectra of 1-CN extracted from a blood sample ( $V=$ $0.5 \mathrm{ml})$ spiked with increasing concentrations of cyanide $\left(\left[\mathrm{CN}^{-}\right]=10-100\right.$ $\mu \mathrm{M})$ according to Fig. $1(\mathbf{1}=42 \mathrm{nmol}$; all measurements were performed 15 min after spiking). ${ }^{16}$

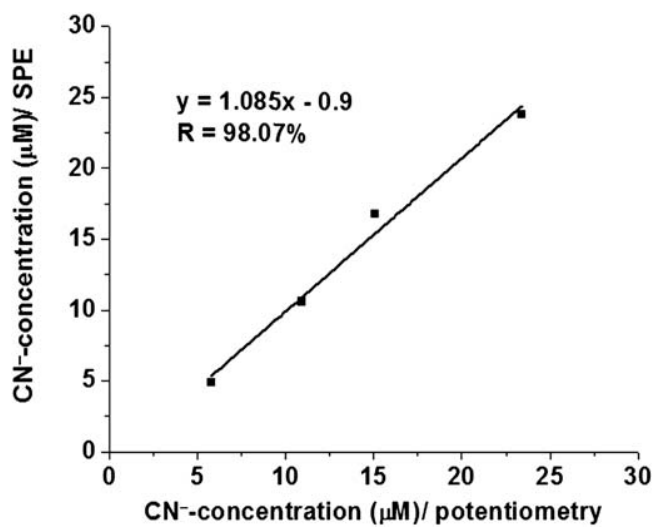

Fig. 5 Results of the determination of different concentrations of cyanide with DRUV-vis spectroscopy using the described SPE-method versus potentiometric measurements using microdistillation. ${ }^{16}$

Hydroxocobalamin, a promising cyanide antidote that is commercially available as Cyanokit $\AA$, basically does not interfere with the detection method as shown in another spiking experiment. ${ }^{16,24}$ Such behaviour is important in monitoring the detoxification process of cyanide poisoning victims with antidotes.

The addition of the reagent to the sample solution before the extraction step is very important. Attempts in which immobilized 1 had been tested for blood cyanide detection did not give satisfactory results. ${ }^{13}$ In these experiments the orange coloured chemosensor had been adsorbed first on the top of the white coloured C18ec column and cyanide spiked blood $\left(V=0.5 \mathrm{ml} ;\left[\mathrm{CN}^{-}\right]=10-100 \mu \mathrm{M}\right)$ was passed through the device afterward. A cyanide transfer to the immobilized chemosensor is apparently not kinetically favoured in this experimental set-up.

Many chemosensors have been recently developed for the detection of cyanide, ${ }^{25-28}$ but only a few work in biological samples. ${ }^{12,29-31}$

We report the first method to rapidly detect blood cyanide with the "naked-eye" and without laboratory equipment. The method is based on the selective colorimetric solid-phase extraction of a hydrophobic violet-coloured chemosensor-cyano complex from a blood sample with a limit of detection of $3 \mu \mathrm{M}$. In contrast to conventional approaches, microdiffusion of gaseous $\mathrm{HCN}$ into a locally seperated detection zone is no longer required. We expect this method to find applications in emergency situations and envisage detecting other analytes following this strategy. 
Support by R. Alberto and the Institute of Inorganic Chemistry of the University of Zurich and G. Patzke for access to their DRUV-vis machines is acknowledged. The authors are thankful to Paul Müller from the Veterinary Clinic of the University of Zurich for supplying fresh animal blood samples.

\section{Notes and references}

1 J. B. Terrill, R. R. Montgomery and C. F. Reinhardt, Science, 1978, 200, 1343-1347.

2 M. Eckstein, JEMS Comm., 2004, 29, 22-31.

3 A. E. Lindsay, A. R. Greenbaum and D. O'Hare, Anal. Chim. Acta, 2004, 511, 185-195.

4 Background Document for Development of WHO Guidelines for Drinking-water Quality, World Health Organization, Geneva, Switzerland, 2007.

5 J. Hamel, Crit. Care Nurse, 2011, 31(1), 72-82.

6 K. E. Murphy, M. M. Schantz, T. A. Butler, B. A. Benner, L. J. Wood and G. C. Turk, Clin. Chem., 2006, 52, 458-467.

7 A. M. Westley and J. Westley, Anal. Biochem., 1989, 181, 190-194.

8 J. Ma, S. I. Ohira, S. K. Mishra, M. Puanngam, P. K. Dasgupta, S. B. Mahon, M. Brenner, W. Blackledge and G. R. Boss, Anal. Chem., 2011, 83, 4319-4324.

9 P. C. do Nascimento, D. Bohrer and L. M. de Carvalho, Analyst, 1998, 123, 1151-1154.

10 B. Madea and B. Brinkmann, in Handbuch Gerichtliche Medizin, Band 2, Springer, Berlin, Heidelberg, New York, 2003, pp. 156-158.

11 C. Lacroix, E. Saussereau, F. Boulanger and J. P. Goull, J. Anal. Toxicol., 2011, 35, 143-147.

12 C. Männel-Croise, B. Probst and F. Zelder, Anal. Chem., 2009, 81, 9493-9498.
13 C. Männel-Croise and F. Zelder, ACS Appl. Mater. Interfaces, 2012, 4, 725-729.

14 S. M. Chemaly, M. Florczak, H. Dirr and H. M. Marques, Inorg. Chem., 2011, 50, 8719-8727.

15 C. Männel-Croise and F. Zelder, Inorg. Chem., 2009, 48, 1272-1274.

16 ESI. $\dagger$

17 O. P. Shvoeva, V. P. Dedkova and S. B. Savvin, J. Anal. Chem., 2001, 56, 1080-1083.

18 M. P. Arena, M. D. Porter and J. S. Fritz, Anal. Chem., 2002, 74, 185190.

19 L. Hannibal, A. Axhemi, A. V. Glushchenko, E. S. Moreira, N. E. Brasch and D. W. Jacobsen, Clin. Chem. Lab. Med., 2008, 46, 1739.

20 L. Xia, A. G. Cregan, L. A. Berben and N. E. Brasch, Inorg. Chem., 2004, 43, 6848-6857.

21 J. C. Harfield, C. Batchelor-McAuley and R. G. Compton, Analyst, 2012, 137, 2285-2296.

22 Inorganic Chemistry of Vitamin B12, ed. J. M. Pratt, Academic Press, New York, 1972.

23 F. H. Zelder, Inorg. Chem., 2008, 47, 1264-1266.

24 www.cyanokit.com.

25 F. H. Zelder and C. Männel-Croise, Chimia, 2009, 63, 58-62.

26 Z. Xu, X. Chen, H. N. Kim and J. Yoon, Chem. Soc. Rev., 2010, 39, $127-137$.

27 Y. Kim, H. Zhao and F. P. Gabbai, Angew. Chem., Int. Ed., 2009, 48, 4957-4960.

28 M. Schmittel and S. Qinghai, Chem. Commun., 2012, 48, 2707-2709.

29 C.-Y. Liu and W.-L. Tseng, Chem. Commun., 2011, 47, 2550-2552.

30 X. Chen, S.-W. Nam, G.-H. Kim, N. Song, Y. Jeong, I. Shin, S. K. Kim, J. Kim, S. Park and J. Yoon, Chem. Commun., 2010, 46, 8953-8955.

31 K. P. Divya, S. Sreejith, B. Balakrishna, P. Jayamurthy, P. Anees and A. Ajayaghosh, Chem. Commun., 2010, 46, 6069-6071. 